\title{
Chapter 15 \\ Investigating In Vivo Myocardial and Coronary Molecular Pathophysiology in Mice with X-Ray Radiation Imaging Approaches
}

\author{
James T. Pearson, Hirotsugu Tsuchimochi, Takashi Sonobe, \\ and Mikiyasu Shirai
}

\subsection{Translating Imaging of Cardiac Function to Small Animals}

Our current approaches to the study of cardiac function and the mechanisms that regulate it in both healthy and disease states rely heavily on biochemical assays of the expression of genes and proteins, extracted from some part of the myocardium. However, we know from studies of the anatomy and physiology of the heart over the past two centuries that in many regards the heart is far from uniform across different regions in its function from the cell to tissue levels. It is easy to forget, when considering molecular analyses, that heart disease too is more often than not, nonuniform in the way it affects the coronary vessels and cardiac muscle. The assessment of myocardial contractile-relaxation properties and coronary vascular function in specific regions of the heart in humans and large experimental animals are two areas in fundamental cardiovascular science and clinical diagnosis that have been greatly aided by the application of various invasive biophysical sensors and non-invasive or less invasive imaging techniques. However, rodents and in particular transgenic mice, are the most common subjects utilized for basic cardiovascular science to discover the mechanisms of disease development and progression and the efficacy of pharmacological and regenerative interventions. Nonetheless, the small physical size of the rodent heart and limitations in the spatial and or temporal resolution of many of the traditional techniques employed to study cardiac and coronary function

Electronic Supplementary Material The online version of this chapter (https://doi.org/ 10.1007/978-981-13-7908-6_15) contains supplementary material, which is available to authorized users.

J. T. Pearson $(\varangle) \cdot$ H. Tsuchimochi $\cdot$ T. Sonobe $\cdot$ M. Shirai

National Cerebral and Cardiovascular Center Research Institute, Suita, Japan

e-mail: jpearson@ncvc.go.jp 
has previously limited such assessments to global measures. Frequently, it has not been possible to make repeated measurements in the same animals in the past.

Herein, we describe our recent progress in the development of in vivo imaging approaches that permit repeated measurements of coronary vascular function utilizing microangiography and local cardiac actin-myosin cross-bridge dynamics utilizing synchrotron radiation (SR) based small angle X-ray scattering (SAXS). This combination of techniques is being used to investigate the important role of the coronary microcirculation in the origins of myocardial disease associated with diabetes, hypertension, obesity and heart failure. For detailed overviews of the cardiovascular application of these techniques, their merits and limitations, the reader is referred to our reviews on synchrotron imaging applications (Shirai et al. 2009, 2013). The high intensity X-ray radiation obtainable at third and fourth generation synchrotron facilities around the world is essential for in situ SAXS recordings from the beating heart in anaesthetised rodents. Lab X-ray sources, routinely used for protein crystallography and SAXS studies of ex vivo samples do not produce sufficient photon flux to enable in vivo recordings with the resolution of several milliseconds. While microangiography performed with SR tuned to energies selective for the elements of contrast imaging agents (such as iodine) facilitates the highest possible temporal and spatial resolution for vascular imaging (see Sect. 15.2.1), the current capabilities of optimized microfocus X-ray systems now permits in vivo imaging of microvessels and has some applications for coronary imaging. Our progress in this area is briefly presented in this chapter (see Sect. 15.3). Before describing how we can apply SAXS and microangiography in our ongoing studies in rats and now mice, we first discuss the motivation for utilizing these techniques.

Synchrotron facilities with the capability of biomedical imaging, including the techniques described in this chapter, are available in many continents. The Lightsources.org webpages (http://www.lightsources.org/) is a useful community based entry point for explanations of synchrotron radiation principles, recent applications and descriptions of the synchrotron facilities available worldwide for non-commercial and commercial research. These webpages also describe access programs for each of these facilities.

\subsection{The Importance of the Microvessels in Sustaining Cardiac Function}

Conduit arteries, which includes the large main left and right coronary arteries and the medium to small artery side branches ( $>300 \mu \mathrm{m}$ internal diameter, ID in humans) serve to distribute blood flow to all regions of the heart. However, the intramural resistance vessels, which primarily includes arterioles $(<150 \mu \mathrm{m}$ ID) and to a lesser extent, small arteries, distribute blood within the myocardial tissue. The majority of coronary resistance is produced by the arterioles, and is determined by the calibre (vessel ID) and the extent of deformation of these vessels during systolic 


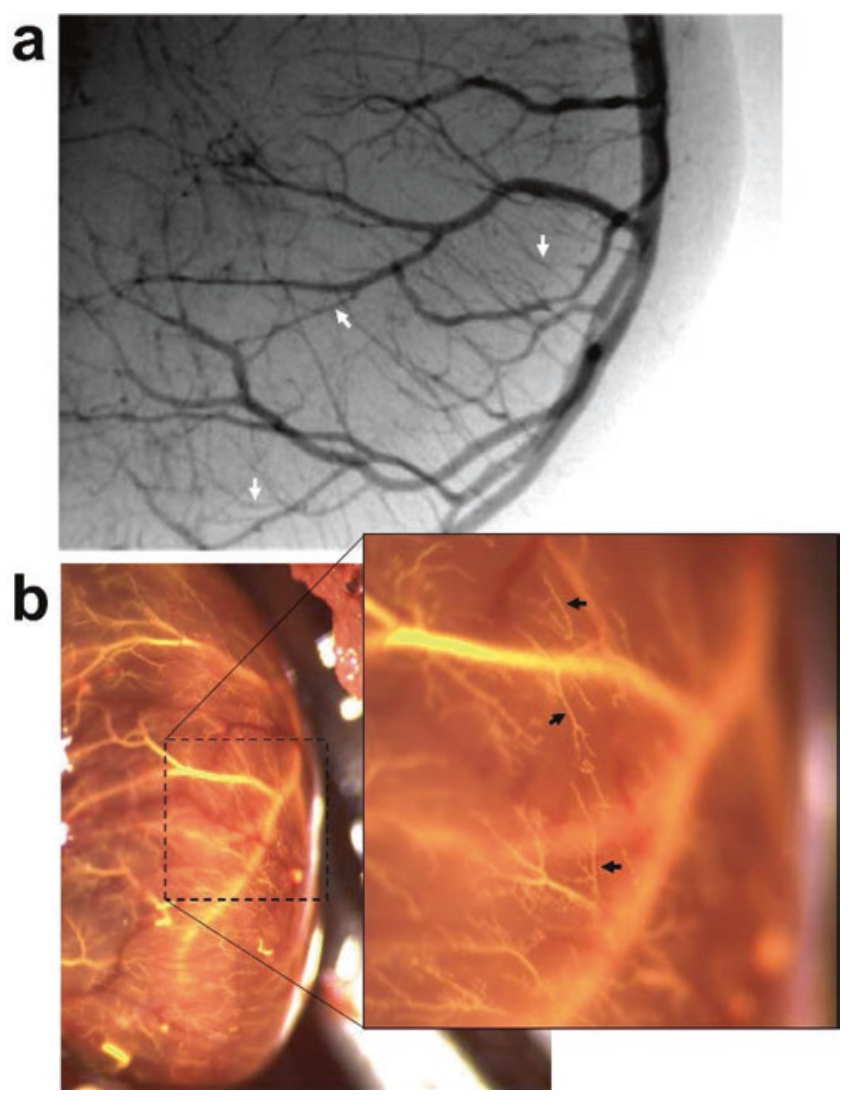

Fig. 15.1 Ex vivo mouse hearts filled with (a) barium gelatin mixture (angiogram) and (b) Microfil ${ }^{\circledR}$ resin (microscope image) in the coronary arterial circulations reveals the extraordinary microvessel density within the obvious network of macrovessels. Arrows indicate $30 \mu \mathrm{m}$ arterioles, which represent the limit of visualization utilising in vivo $2 \mathrm{D} \mathrm{X}$-ray angiography

contractions (Camici et al. 2012). As can be appreciated from Fig. 15.1, the capillary and arteriole microvessel network of the myocardium is very extensive. Interspersed between the muscle fibres the capillary density varies from a little over $2000 / \mathrm{mm}^{2}$ in mice to more than $3000 / \mathrm{mm}^{2}$ in dogs (Bassingthwaighte et al. 1974; $\mathrm{Xu}$ et al. 2016). Notably, utilizing clinical angiography in humans it is not possible to visualize the microvessels. The smallest vessels evident in clinical angiograms are small artery conduit vessels (Fig. 15.2).

Coronary regulation of the larger microvessels acts to adjust local blood flow to meet metabolic demands. An increase in cardiac work during stress and exercise is facilitated by an increase in coronary flow through the opening of side branches and more distal segments of the vascular tree (vasodilation). The ratio or the maximal increase in coronary flow above resting level is referred to as coronary flow reserve 

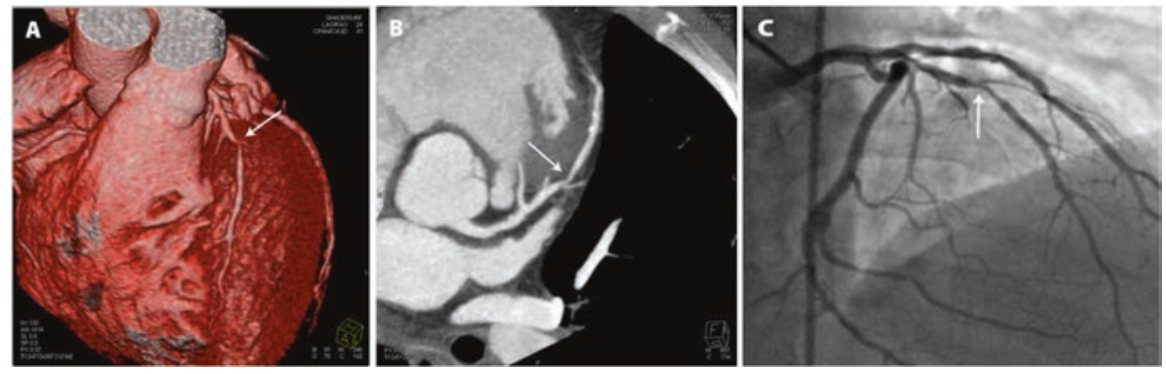

Fig. 15.2 Clinical CT (a, b) is not able to resolve microvessels, and the smallest visible vessels observed with clinical angiography (c) are small to medium arteries ( $>200 \mu \mathrm{m}$ internal diameter). (Reproduced from Rao and Thompson 2011)

and is a useful index of the health of the coronary circulation. Coronary flow reserve can be determined by positron emission tomography, myocardial contrast echocardiography or invasively with electromagnetic flow probes, cine-angiography or the thermodilution technique. Regardless of the technique used, coronary flow reserve is an integrated measure of blood flow changes across the whole myocardium, including the large coronary arteries and the microvessels, and while very informative, it does not inform on how blood flow is distributed between vessel types or regions. However, direct visualization of coronary vascular responses during cine-angiography does permit analysis of regional changes in blood flow in terms of flow velocity, vessel calibre and visible vessel number. Hence, cine-angiography provides opportunities to investigate changes in coronary function in healthy and disease states.

Various studies now reveal that microvascular function impairment is an important contributor to the progression of many forms of heart failure, including hereditary and non-hereditary forms of hypertrophic cardiomyopathy (Olivotto et al. 2011; Camici et al. 2012), and the increasingly prevalent forms of heart failure with preserved ejection fraction (HFpEF) and angina (Franssen et al. 2016; Crea et al. 2017). There is growing evidence that endothelial dysfunction and ongoing vascular inflammation contribute not only to progressive rarefaction of coronary microvessels (Mohammed et al. 2015), but also increased stiffness and impaired relaxation of cardiac muscle (Franssen et al. 2016; Crea et al. 2017). Reduced nitric oxide bioavailability in the cardiomyocytes surrounding the microvessels is associated with diminished protein kinase $\mathrm{G}$ activity and reduced phosphorylation of the giant sarcomeric protein titin, and thus, increased passive tension (one component of muscle stiffening) of the sarcomeres and promotion of ventricular hypertrophy (Borbely et al. 2009; van Heerebeek et al. 2012; Paulus and Tschöpe 2013; Franssen et al. 2016). However, the roles of other vasodilators have not been considered in the current paradigm that links microvessel endothelial inflammation to the origins of HFpEF. It is well established that endothelium derived hyperpolarization factors (EDHF) are important for the regulation of microvessel flow and coronary flow reserve during exercise. Diabetes, obesity, hypertension and aging all impair 
microvessel EDHF production and or transmission of the hyperpolarization signal through the vessel wall (Park et al. 2008; Luksha et al. 2009; Jenkins et al. 2012; Behringer et al. 2013; Feher et al. 2014; Beyer et al. 2016; Chen et al. 2016; Garland and Dora 2016). Moreover, an imbalance of vasoconstrictor factors, including endothelin-1, rho-kinase and serotonin also contribute to vascular dysfunction in the same comorbidities, which in combination drive the development of HFpEF. Therefore, the roles of other vasodilators and vasoconstrictors in the deterioration of coronary flow reserve, myocardial contractile reserve and diastolic dysfunction remain to be investigated.

\subsubsection{The Challenges Associated with Investigating Coronary Microvascular Function}

How then do we assess the presence of endothelial dysfunction, particularly in the microvessels? Conventional cine-angiography using clinical radiography systems does not permit visualization of the coronary microvessels as low photon flux and collimation limit vessel resolution to vessels $>200 \mu \mathrm{m}$ ID (Shirai et al. 2013) (Fig. 15.2). Despite the advances in clinical computed tomography (CT) angiography with dual-energy multidetector systems, these systems still have a spatial resolution less than that of clinical cine-angiography, and therefore only medium to large arteries can be resolved. However, in rodents the coronary arterioles are $40-100 \mu \mathrm{m}$ ID and can readily be visualized with SR microangiography (Jenkins et al. 2012; Pearson et al. 2017) (Fig. 15.3). This approach facilitates investigations of endothelial and smooth muscle function during pharmacological stimulation in anaesthetised rodents in vivo. The main advantage of this SR cine-angiography approach is that it enables in vivo analysis of vascular function at the same time in multiple arterial vessels across the micro- to macrovessel network under
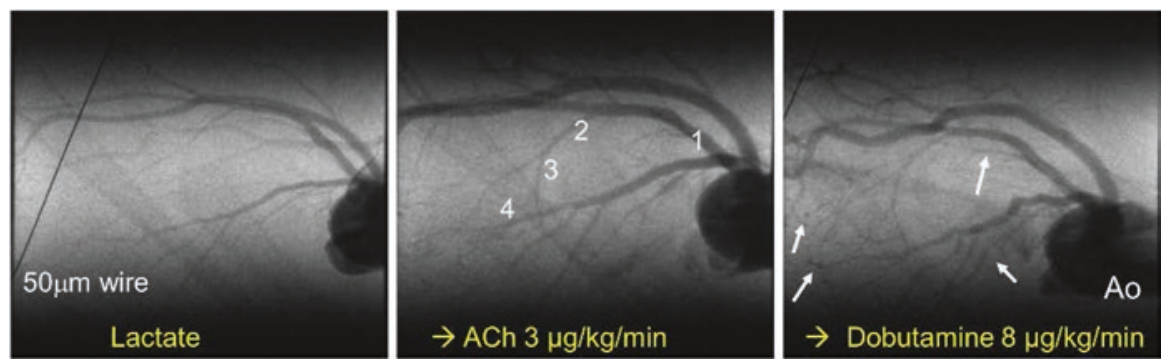

Fig. 15.3 Assessment of endothelial function in the coronary circulation in vivo in a male Sprague Dawley rat. (a) baseline vehicle infusion, (b) acetylcholine (ACh) administration, (c) dobutamine administration. Numerals show four branching orders of arterial vessels. ACh and dobutamine stimulation evoked dilation and an increase in visible vessel number (white arrows) 
physiological conditions and with intact neurohormonal regulation, which is important for research translation. Further, it is possible to repeat imaging many times during pharmacological stimulation and the manipulation of cardiac loading conditions. An important limitation is the tradeoff for imaging at pixel resolutions of $10-15 \mu \mathrm{m}$ is that generally available optic chips have arrays of $1024 \times 1024$ or $2048 \times 2048$ pixels, limiting the maximum observable field of view to $1-3 \mathrm{~cm}$.

We utilize direct arterial injection of bolus amounts of commercial iodinated contrast agents. The increased viscosity of pure contrast agent requires that contrast be injected with a fast syringe pump via an arterial catheter that is as short as possible to reduce resistance to bolus delivery, and placed as close to target vessels as possible. Typically, paediatric radiography catheters can be used for adult and adolescent rats and hamsters, but for studies utilizing mice then tapered or step-down catheters are essential. Polyethylene or polyurethane catheters with an outer diameter of $1.2 \mathrm{~F}(0.4 \mathrm{~mm})$, such as a cut down version of the FunnelCath ${ }^{\mathrm{TM}}$, can successfully deliver contrast agent boluses in mice in $\sim 1 \mathrm{~s}$ if the distal narrow tube is shortened (a simple manual test can confirm the ideal length for bolus injection) (Pearson et al. 2017). Furthermore, in the case of coronary angiography in rodents, ideal coronary cine-angiograms can only be obtained if the tip of the catheter is inserted retrograde via the right carotid artery (most direct route) up to a position immediately behind the aortic valve, otherwise left ventricle pumping greatly dilutes contrast concentration and entry into the coronary arteries. When inserting narrow gauge catheters in mice the use of a guidewire is sometimes needed to assist catheter insertion when vascular remodeling makes the artery wall increasingly fragile.

\subsubsection{Protocols for Assessment of Coronary Endothelial Function}

As demonstrated in Fig. 15.3 with current X-ray detectors it is possible to acquire coronary angiograms at physiological heart rates (300-700 bpm) free from motion artefacts, even at video frame rates, utilizing shutters placed in the X-ray beam to reduce single frame exposure times to $1-5 \mathrm{~ms}$. High speed detectors operating at 50-100 Hz with high sensitivity phosphor plates eliminate the need for shutters for imaging acquisition, but such shutters serve to reduce surface entry radiation dose when image acquisitions are repeated many times in the same animals. Furthermore, motion-induced artefacts during coronary imaging are nearly eliminated by briefly sustaining lung volume at end inspiration (a breath hold 3-4 s), without significantly altering haemodynamics.

Single frames from cine-sequences acquired from two mice during a drug stimulation protocol ( $\sim 1 \mathrm{~h}$ duration) are illustrated in Fig. 15.4. In this study (Pearson 

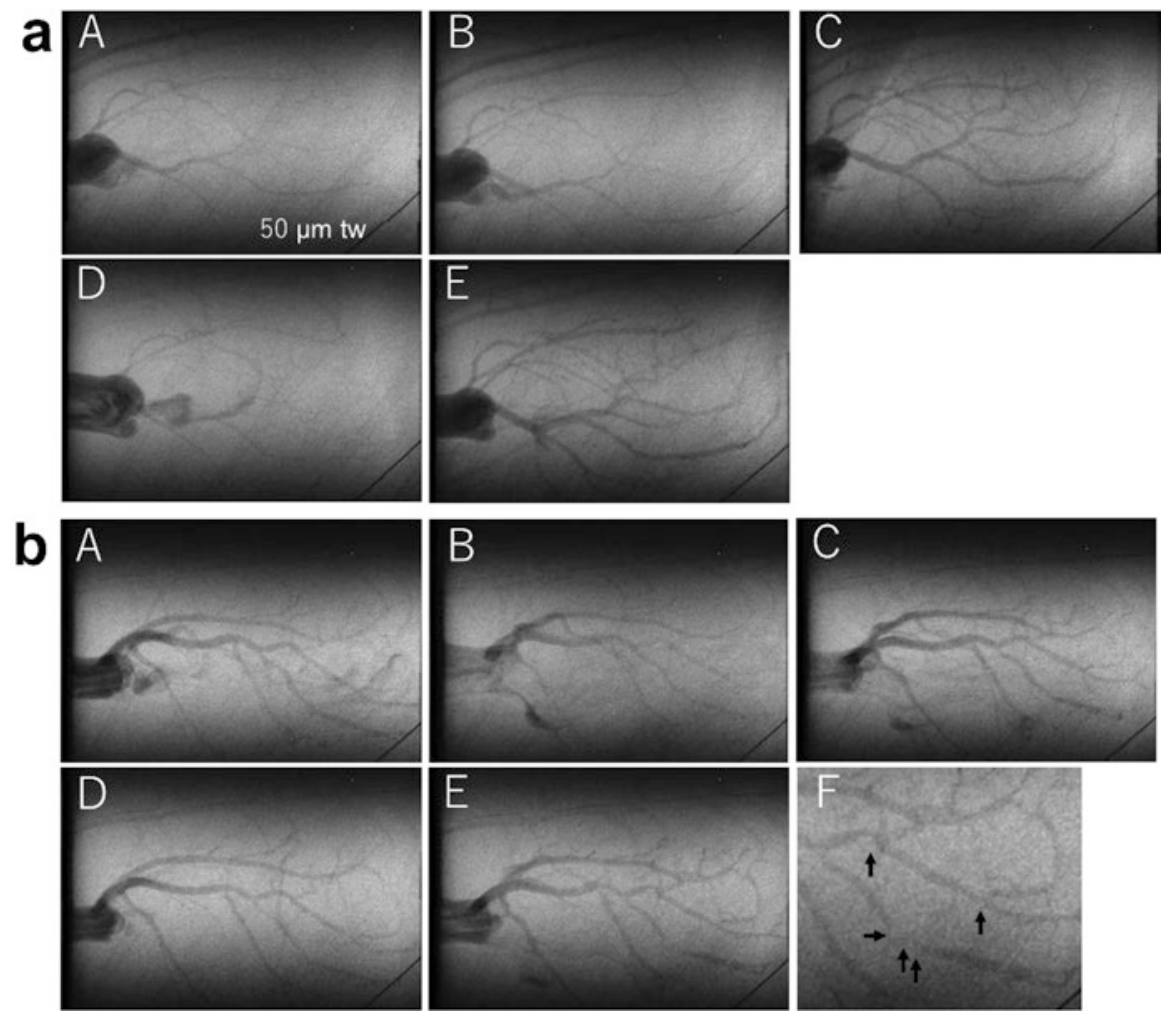

Fig. 15.4 Vascular responses to drug stimulation (a) in a mouse with SR-B1 protein present in blood vessels compared with (b) in a mouse deficient in SR-B1 protein. During baseline (A), ACh (B), sodium nitroprusside (C), blockade of nitric oxide and prostaglandins (D), blockade and ACh (E), enlargement of panel E illustrating stenoses (black arrows) in deficient mouse (F). (Reproduced from Pearson et al. 2017)

et al. 2017) we examined how the absence of a scavenger receptor class B (SR-B1) protein affected the global and regional regulation of coronary vasodilation in the microcirculation utilizing a transgenic mouse model exposed transiently to a high fat diet, which induces coronary plaque lesion formation. Not only were we able to show that SR cine-angiography could reveal partial occlusions (black arrows in b, stenoses confirmed by histology to be due to occlusive plaque formation, Fig. 15.4) in macrovessels, but also that smooth muscle dysfunction was present globally in non-occluded microvessels (Pearson et al. 2017).

We have successfully transferred coronary SR cine-angiography protocols to enable assessment of coronary vascular function in normal and transgenic mouse 
Fig. 15.5 Routine protocols for investigating endothelium-dependent and independent vasodilation in rodents with consecutive drug stimulations

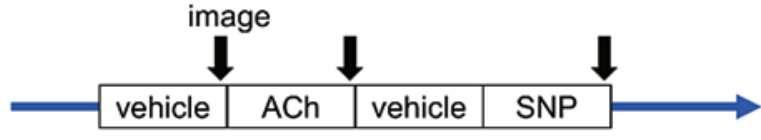

5 min infusions

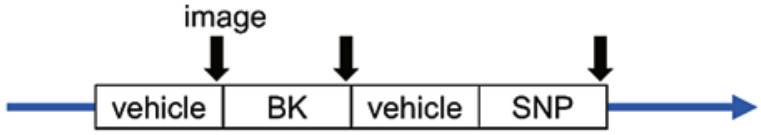

5 min infusions

models (Shirai et al. 2013). While assessment of coronary flow reserve can be performed with adenosine or dobutamine stress test in mice, as shown for a rat in Fig. 15.3, it is often desired to assess coronary endothelial function during disease progression and following pharmacological intervention. Two simple protocols are illustrated that allow the assessment of endothelial dysfunction in mice by evaluating the changes in coronary vessel calibre and visible vessel number mediated by endothelium-dependent and independent dilation induced by agonist stimulation (Fig. 15.5). Continuous infusion of acetylcholine (ACh) or bradykinin (BK) solutions $(0.1 \mathrm{mg} / \mathrm{ml})$ at flow rates of $3 \mu \mathrm{l} / \mathrm{min}$ in a $30 \mathrm{~g}$ mouse or $2 \mu \mathrm{l} / \mathrm{min}$ in a $20 \mathrm{~g}$ mouse $(10 \mu \mathrm{g} / \mathrm{kg} / \mathrm{min})$ evoke endothelium-dependent dilation. It has been demonstrated many times that $\mathrm{ACh}$ and $\mathrm{BK}$ can evoke dilation through nitric oxide or endothelium-derived hyperpolarization factors (Batenburg et al. 2004, 2005; Bergaya et al. 2004; Jenkins et al. 2012; Chen et al. 2016). In order to establish whether the lack of a response to ACh stimulation is due to endothelial dysfunction in any given vascular bed it is common practice to subsequently stimulate the vessels with sodium nitroprusside (SNP, $10 \mu \mathrm{g} / \mathrm{kg} / \mathrm{min}$ ), a nitric oxide donor, after a suitable washout period. SNP evokes endothelium-independent dilation in the absence of smooth muscle dysfunction. Therefore, if a mouse shows dilation to $\mathrm{SNP}$, but not $\mathrm{ACh}$, then this is taken to be evidence of endothelial dysfunction. On the other hand, in models where vessels do not show dilation to SNP then this is taken to be evidence of smooth muscle dysfunction, at least in respect to nitrergic signaling within the smooth muscle. If vessels do not respond with dilation to either ACh or SNP it is not possible to establish that endothelial dysfunction is present since there is underlying smooth muscle dysfunction downstream of the endothelium, unless the same vessels also fail to dilate to BK, which can evoke hyperpolarization independent of nitric oxide. Hence, utilizing multiple endothelium-dependent agonists to investigate endothelial function is recommended where possible. If the presence of smooth muscle dysfunction is indicated by a lack of response to SNP, then further investigation of the mechanism involved can be achieved by also utilizing adenosine or large-conductance $\mathrm{Ca}^{2+}$-activated $\mathrm{K}^{+}$channel agonists to determine which relaxation mechanisms are dysfunctional (Batenburg et al. 2005). 


\subsection{Progress in Vascular Imaging of Small Animals with Lab Systems}

Preclinical microCT systems are commercially available that enable CT angiography in animals up to the size of rabbits. However, effective pixel size for single projection images on the CMOS flat-panel detectors with a field of view of several $\mathrm{cm}^{3}$ is typically $100-200 \mu \mathrm{m}$. With such systems 2D angiography can at best reveal small arteries. Higher resolution acquisitions are only possible for ex vivo 3D acquisitions due to the prolonged scanning times ( $>5 \mathrm{~min}$ ). Nonetheless, microfocus X-ray imaging systems are available that are suitable for real time imaging of the microvessels in vivo, but the challenge has been achieving fast imaging with sufficient absorption contrast to visualize vessels in organs that move, the heart and lungs. One such system that we have utilized for investigations of the hindlimb vasculature in peripheral arterial disease associated with diabetes is the Hitex system described in our recent study (Sonobe et al. 2015).

Utilising an optimised microfocus X-ray system (MFX-80HK, Hitex Ltd., Osaka, Japan) incorporating an off the shelf high speed camera with ultrasensitivity (FASTCAM Mini AX200, Photron, Japan) we have greatly improved the possibilities for real time cine-angiography in rats and mice (Fig. 15.6). The current capability of this system suggests that microvessel function studies approach the real resolution of SR microangiography in the hindlimb, brain and renal vessel beds (with frame averaging). However, limited photon counts at the detector result in blur and unsatisfactory vessel edge detection in single projection images of the coronary and pulmonary arteries below $100 \mu \mathrm{m}$. Further optimization of the image intensifier and X-ray source might lead to the development of a system that permits assessment of coronary endothelial function in vivo during closed-chest conditions in the laboratory.

\subsection{Application of In Vivo SAXS to the Study of Myocardial Function in Mice}

Various research groups currently employ SAXS for muscle diffraction studies of contraction-relaxation mechanisms in cardiac muscle ex vivo, which is complemented by cell approaches to investigate excitation-contraction coupling in isolated cardiomyocytes. This can be routinely achieved with dedicated lab X-ray SAXS systems, but real-time analysis of myofilament function is achieved with SR as an X-ray source. We and others have developed approaches for SAXS investigations in the beating heart in situ utilizing rats and more recently mice (Pearson et al. 2004, 2007; Yagi et al. 2004; Toh et al. 2006; Shirai et al. 2013).

Actin and myosin filaments form the bulk of sarcomeric proteins, along with titin, but only the lattice like arrangement of actin-myosin produces diffraction 

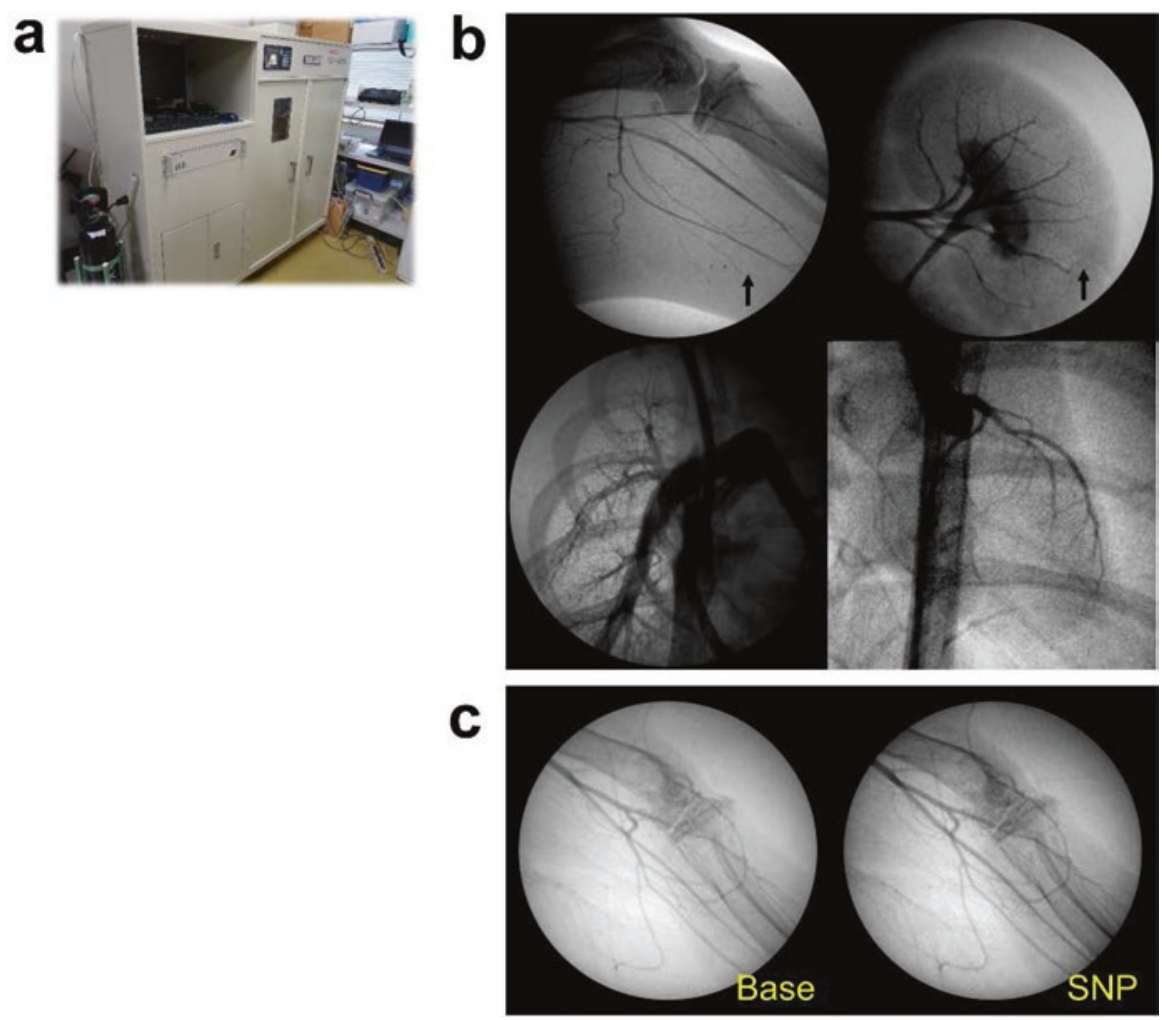

Fig. 15.6 (a) Microfocus X-ray video system (Hitex, Osaka, Japan) optimized for laboratory based imaging (iodine contrast agent) and examples of image quality achieved while imaging anaesthetised (b) rats (hindlimb, kidney, pulmonary and coronary arteries) and (c) mice (hindlimb), acquired at 250 frames/s, $60 \mathrm{kV}$ and $80 \mu \mathrm{A}$. Black arrows indicate $50 \mu \mathrm{m}$ arterioles in the hindlimb and renal cortex

reflections when a high energy X-ray beam $(0.1 \times 0.2 \mathrm{~mm})$ is aligned perpendicular to the myocardial fibre direction (Shirai et al. 2013). The intensity of the two major reflections produced depends on the electron mass distribution around the filaments, which changes during the cross-bridge cycle as myosin heads shift between the myosin backbone and the surrounding actin filaments (Fig. 15.7). The diffraction pattern acquired at $10-15 \mathrm{~ms}$ intervals from a beam passing through the exposed heart of a supine anaesthetised rodent is sufficient to track the changes in myosin mass transfer over the cardiac cycle for several seconds (Pearson et al. 2004). The intensity of the 1,0 reflection decreases as myosin heads are extended towards actin and form force-developing cross-bridge attachments. This myosin mass transfer provides a simple index of the number of cross-bridge attachments formed, which is highly correlated with developed force and left ventricular pressure at systole. 

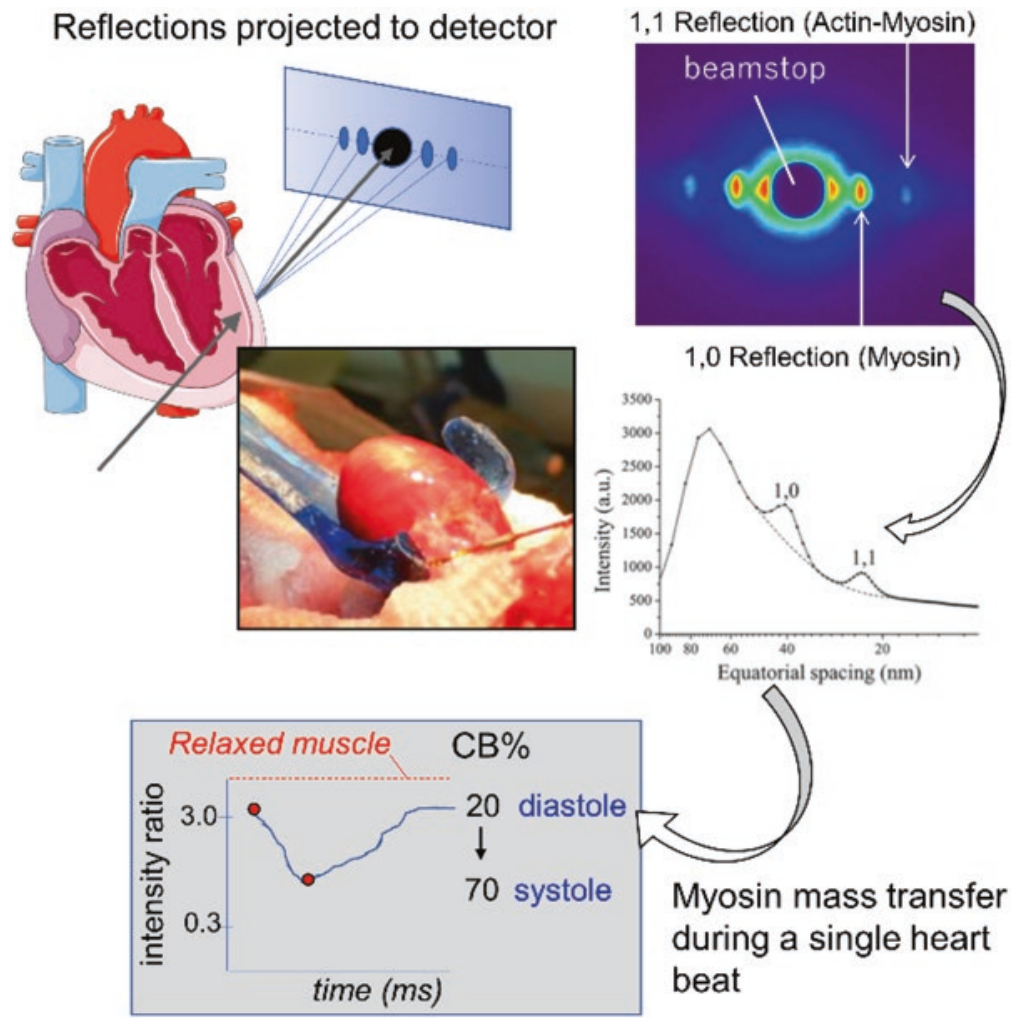

Fig. 15.7 In situ small angle X-ray scattering based investigations of regional cardiac contractile function. Diffraction pattern recorded in a $15 \mathrm{~ms}$ interval, and a typical intensity profile and the calculated intensity ratio change over the cardiac cycle

In recent years we and others have shown that this in vivo approach can be utilized to investigate regional differences in myocardial function and even differences across the myocardial wall from the epicardium to the subendocardium based on the trajectory of the X-ray beam (Jenkins et al. 2013; Shirai et al. 2013; Waddingham et al. 2015). Using this approach, we showed that altered kinase activity and changes in phosphorylation state of the various myofilaments in diabetes contributes to the early origins of diastolic dysfunction (Fig. 15.8). Further, others have shown with ex vivo SAXS that altered protein kinase activity in cardiac hypertrophy contributes to an increase in passive stiffness associated with more myosin heads remaining in the proximity of actin filaments (Sumita Yoshikawa et al. 2013).

Since the first SAXS studies on cross-circulated canine hearts, then spontaneously beating rat hearts, there has been only one study that investigated in situ crossbridge interactions and myosin mass transfer simultaneous with electrocardiogram 
a

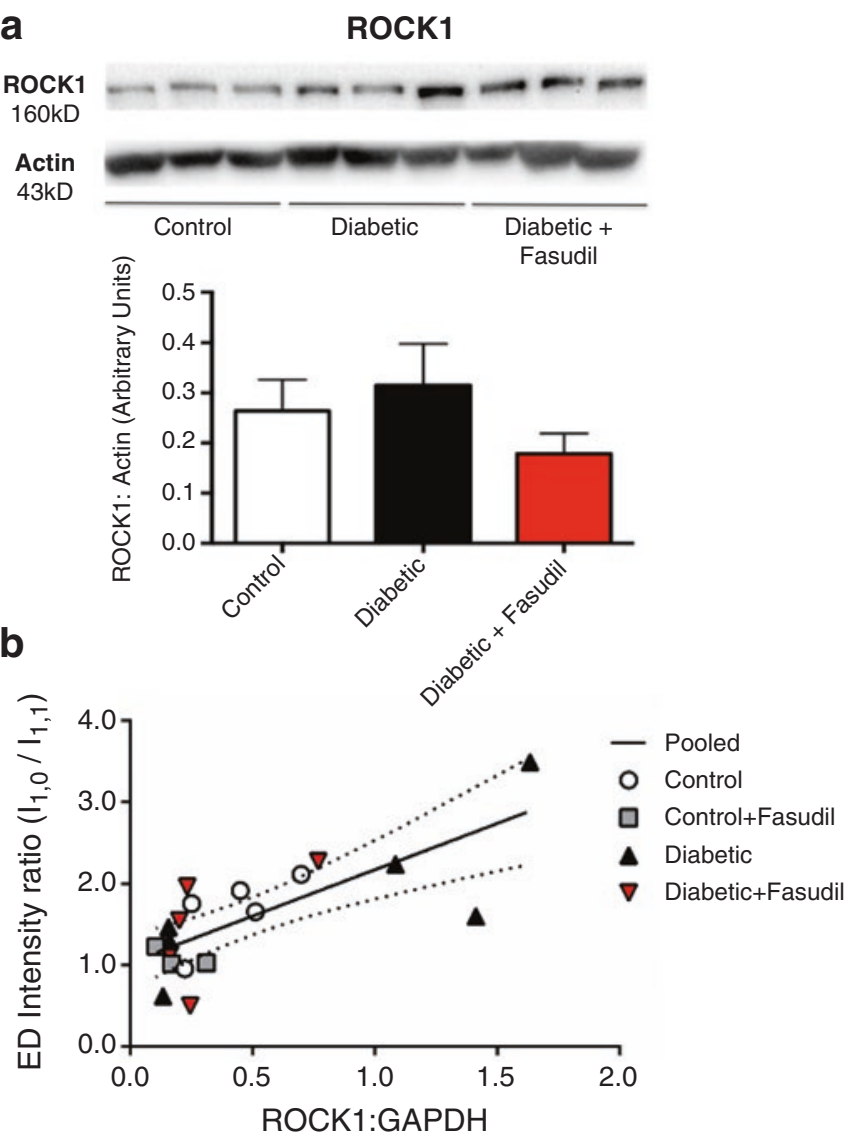

Fig. 15.8 (a) Direct relation between rho-kinase (ROCK1) protein expression in the myocardium of rats and (b) the measured diastolic (ED) intensity ratio determined from X-ray diffraction patterns. Results shown include non-diabetic (control) and diabetic rats treated with ROCK inhibitor fasudil. Reproduced from Waddingham et al. (2015)

in the mouse heart (Toh et al. 2006). Now we have been able to apply cardiac muscle diffraction recordings simultaneous with left ventricle pressure-volume recordings in transgenic mice, and again use this approach to measure myosin mass transfer across the cardiac cycle in different layers of the left ventricle (Fig. 15.9). Ongoing studies are now investigating myofilament dysfunction with aging in a knockin mouse model of human familial cardiac hypertrophy. This opens the possibilities of new investigations into cardiomyopathies and heart failure using cell-specific or receptor-ligand specific knock down or knockin and even conditional knockouts to 
Fig. 15.9 Calculated equatorial reflection intensity ratio over the cardiac cycle in a normal wild type mouse over a 2-s recording (10 ms intervals). red dashed line indicates ratio obtained in

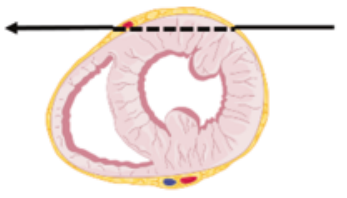

X-ray beam path through anterior wall

Subendocardium mass transfer the heart arrested in diastole (state with no cross-bridge attachments)

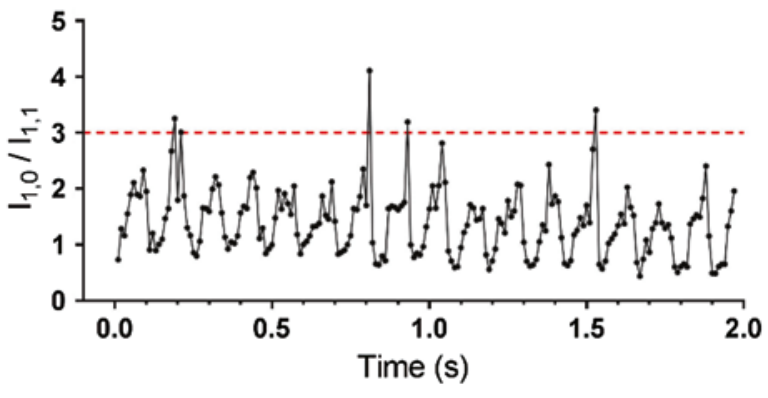

probe the underlying mechanisms associated with myofilament dysfunction due to altered myocardial energetics and calcium overload, changes in intracellular protein kinase signaling or increased myocardial oxidative stress and inflammation.

Acknowledgments The authors gratefully acknowledge support from the Uehara Memorial Foundation. All experiments performed at the Japan Synchrotron Radiation Research Institute with approval of the SPring-8 Animal Experiment Review Committee (proposals 2012A1674, 2013B1767, 2015A1354, 2015B1533, 2017A1324).

\section{References}

Bassingthwaighte JB, Yipintsoi T, Harvey RB (1974) Microvasculature of the dog left ventricular myocardium. Microvasc Res 7(2):229-249. https://doi.org/10.1016/0026-2862(74)90008-9

Batenburg WW, Garrelds IM, van Kats JP, Saxena PR, Danser AH (2004) Mediators of bradykinininduced vasorelaxation in human coronary microarteries. Hypertension (Dallas, Tex : 1979) 43(2):488-492. https://doi.org/10.1161/01.hyp.0000110904.95771.26

Batenburg WW, Tom B, Schuijt MP, Danser AH (2005) Angiotensin II type 2 receptor-mediated vasodilation. Focus on bradykinin, NO and endothelium-derived hyperpolarizing factor(s). Vasc Pharmacol 42(3):109-118. https://doi.org/10.1016/j.vph.2005.01.005

Behringer EJ, Shaw RL, Westcott EB, Socha MJ, Segal SS (2013) Aging impairs electrical conduction along endothelium of resistance arteries through enhanced $\mathrm{Ca} 2+$-activated $\mathrm{K}+$ channel activation. Arterioscler Thromb Vasc Biol 33(8):1892-1901. https://doi.org/10.1161/ atvbaha.113.301514 
Bergaya S, Hilgers RH, Meneton P, Dong Y, Bloch-Faure M, Inagami T, Alhenc-Gelas F, Levy BI, Boulanger CM (2004) Flow-dependent dilation mediated by endogenous kinins requires angiotensin AT2 receptors. Circ Res 94(12):1623-1629. https://doi.org/10.1161/01. RES.0000131497.73744.1a

Beyer AM, Zinkevich N, Miller B, Liu Y, Wittenburg AL, Mitchell M, Galdieri R, Sorokin A, Gutterman DD (2016) Transition in the mechanism of flow-mediated dilation with aging and development of coronary artery disease. Basic Res Cardiol 112(1):5. https://doi.org/10.1007/ s00395-016-0594-x

Borbely A, van Heerebeek L, Paulus WJ (2009) Transcriptional and posttranslational modifications of titin: implications for diastole. Circ Res 104(1):12-14. https://doi.org/10.1161/ circresaha.108.191130

Camici PG, Olivotto I, Rimoldi OE (2012) The coronary circulation and blood flow in left ventricular hypertrophy. J Mole Cell Cardiol 52(4):857-864. https://doi.org/10.1016/j.yjmcc.2011.08.028

Chen YC, Inagaki T, Fujii Y, Schwenke DO, Tsuchimochi H, Edgley AJ, Umetani K, Zhang Y, Kelly DJ, Yoshimoto M, Nagai H, Evans RG, Kuwahira I, Shirai M, Pearson JT (2016) Chronic intermittent hypoxia accelerates coronary microcirculatory dysfunction in insulin-resistant Goto-Kakizaki rats. Am J Physiology Reg Integ Comp Physiol 311(2):R426-R439. https://doi. org/10.1152/ajpregu.00112.2016

Crea F, Bairey Merz CN, Beltrame JF, Kaski JC, Ogawa H, Ong P, Sechtem U, Shimokawa H, Camici PG (2017) The parallel tales of microvascular angina and heart failure with preserved ejection fraction: a paradigm shift. Eur Heart J 38(7):473-477. https://doi.org/10.1093/ eurheartj/ehw461

Feher A, Broskova Z, Bagi Z (2014) Age-related impairment of conducted dilation in human coronary arterioles. Am J Physiol Heart Circ Physiol 306(12):H1595-H1601. https://doi. org/10.1152/ajpheart.00179.2014

Franssen C, Chen S, Unger A, Korkmaz HI, De Keulenaer GW, Tschöpe C, Leite-Moreira AF, Musters R, Niessen HWM, Linke WA, Paulus WJ, Hamdani N (2016) Myocardial microvascular inflammatory endothelial activation in heart failure with preserved ejection fraction. JACC: Heart Failure 4(4):312-324. https://doi.org/10.1016/j.jchf.2015.10.007

Garland CJ, Dora KA (2016) EDH: endothelium-dependent hyperpolarization and microvascular signaling. Acta Physiol (Oxf) 219:152-161. https://doi.org/10.1111/apha.12649

Jenkins MJ, Edgley AJ, Sonobe T, Umetani K, Schwenke DO, Fujii Y, Brown RD, Kelly DJ, Shirai M, Pearson JT (2012) Dynamic synchrotron imaging of diabetic rat coronary microcirculation in vivo. Arterioscler Thromb Vasc Biol 32(2):370-U466. https://doi.org/10.1161/ atvbaha.111.237172

Jenkins MJ, Pearson JT, Schwenke DO, Edgley AJ, Sonobe T, Fujii Y, Ishibashi-Ueda H, Kelly DJ, Yagi N, Shirai M (2013) Myosin heads are displaced from actin filaments in the in situ beating rat heart in early diabetes. Biophys J 104(5):1065-1072. https://doi.org/10.1016/j. bpj.2013.01.037

Luksha L, Agewall S, Kublickiene K (2009) Endothelium-derived hyperpolarizing factor in vascular physiology and cardiovascular disease. Atherosclerosis 202(2):330-344. https://doi. org/10.1016/j.atherosclerosis.2008.06.008

Mohammed SF, Hussain S, Mirzoyev SA, Edwards WD, Maleszewski JJ, Redfield MM (2015) Coronary microvascular rarefaction and myocardial fibrosis in heart failure with preserved ejection fraction. Circulation 131(6):550-559. https://doi.org/10.1161/circulationaha.114.009625

Olivotto I, Girolami F, Sciagra R, Ackerman MJ, Sotgia B, Bos JM, Nistri S, Sgalambro A, Grifoni C, Torricelli F, Camici PG, Cecchi F (2011) Microvascular function is selectively impaired in patients with hypertrophic cardiomyopathy and sarcomere myofilament gene mutations. J Am Coll Cardiol 58(8):839-848. https://doi.org/10.1016/j.jacc.2011.05.018 
Park Y, Capobianco S, Gao X, Falck JR, Dellsperger KC, Zhang C (2008) Role of EDHF in type 2 diabetes-induced endothelial dysfunction. Am J Physiol Heart Circ Physiol 295(5):H1982H1988. https://doi.org/10.1152/ajpheart.01261.2007

Paulus WJ, Tschöpe C (2013) A novel paradigm for heart failure with preserved ejection fraction. J Am Coll Cardiol 62(4):263-271. https://doi.org/10.1016/j.jacc.2013.02.092

Pearson JT, Shirai M, Ito H, Tokunaga N, Tsuchimochi H, Nishiura N, Schwenke DO, IshibashiUeda H, Akiyama R, Mori H, Kangawa K, Suga H, Yagi N (2004) In situ measurements of crossbridge dynamics and lattice spacing in rat hearts by $\mathrm{x}$-ray diffraction: sensitivity to regional ischemia. Circulation 109(24):2976-2979

Pearson JT, Shirai M, Tsuchimochi H, Schwenke DO, Ishida T, Kangawa K, Suga H, Yagi N (2007) Effects of sustained length-dependent activation on in situ cross-bridge dynamics in rat hearts. Biophys J 93(12):4319-4329. https://doi.org/10.1529/biophysj.107.111740

Pearson JT, Yoshimoto M, Chen YC, Sultani R, Edgley AJ, Nakaoka H, Nishida M, Umetani K, Waddingham MT, Jin H-L, Zhang Y, Kelly DJ, Schwenke DO, Inagaki T, Tsuchimochi H, Komuro I, Yamashita S, Shirai M (2017) Widespread coronary dysfunction in the absence of HDL receptor SR-B1 in an ischemic cardiomyopathy mouse model. Sci Rep 7(1):18108. https://doi.org/10.1038/s41598-017-18485-6

Rao SC, Thompson RC (2011) Coronary CT angiography as an alternative to invasive coronary angiography. In: Baskot B (ed) Coronary angiography - advances in noninvasive imaging approach for evaluation of coronary artery disease. InTech, Rijeka, p Ch. 06. https://doi. org/10.5772/21191

Shirai M, Schwenke DO, Eppel GA, Evans RG, Edgley AJ, Tsuchimochi H, Umetani K, Pearson JT (2009) Synchrotron-based angiography for investigation of the regulation of vasomotor function in the microcirculation in vivo. Clin Exper Pharmacol Physiol 36(1):107-116. https:// doi.org/10.1111/j.1440-1681.2008.05073.x

Shirai M, Schwenke DO, Tsuchimochi H, Umetani K, Yagi N, Pearson JT (2013) Synchrotron radiation imaging for advancing our understanding of cardiovascular function. Circ Res 112(1):209-221. https://doi.org/10.1161/circresaha.111.300096

Sonobe T, Tsuchimochi H, Schwenke DO, Pearson JT, Shirai M (2015) Treadmill running improves hindlimb arteriolar endothelial function in type 1 diabetic mice as visualized by X-ray microangiography. Cardiovasc Diabetol 14:51. https://doi.org/10.1186/s12933-015-0217-0

Sumita Yoshikawa W, Nakamura K, Miura D, Shimizu J, Hashimoto K, Kataoka N, Toyota H, Okuyama H, Miyoshi T, Morita H, Fukushima Kusano K, Matsuo T, Takaki M, Kajiya F, Yagi N, Ohe T, Ito H (2013) Increased passive stiffness of cardiomyocytes in the transverse direction and residual actin and myosin cross-bridge formation in hypertrophied rat hearts induced by chronic $\beta$-adrenergic stimulation. Circ J 77(3):741-748. https://doi.org/10.1253/ circj.CJ-12-0779

Toh R, Shinohara M, Takaya T, Yamashita T, Masuda S, Kawashima S, Yokoyama M, Yagi N (2006) An $x$-ray diffraction study on mouse cardiac cross-bridge function in vivo: effects of adrenergic $\beta$-stimulation. Biophys J 90(5):1723-1728. https://doi.org/10.1529/biophysj.105.074062

van Heerebeek L, Hamdani N, Falcao-Pires I, Leite-Moreira AF, Begieneman MP, Bronzwaer JG, van der Velden J, Stienen GJ, Laarman GJ, Somsen A, Verheugt FW, Niessen HW, Paulus WJ (2012) Low myocardial protein kinase G activity in heart failure with preserved ejection fraction. Circulation 126(7):830-839. https://doi.org/10.1161/circulationaha.111.076075

Waddingham MT, Edgley AJ, Astolfo A, Inagaki T, Fujii Y, Du C-K, Zhan D-Y, Tsuchimochi H, Yagi N, Kelly DJ, Shirai M, Pearson JT (2015) Chronic rho-kinase inhibition improves left ventricular contractile dysfunction in early type-1 diabetes by increasing myosin cross-bridge extension. Cardiovasc Diabetol 14:92. https://doi.org/10.1186/s12933-015-0256-6 
Xu H, van Deel ED, Johnson MR, Opić P, Herbert BR, Moltzer E, Sooranna SR, van Beusekom H, Zang W-F, Duncker DJ, Roos-Hesselink JW (2016) Pregnancy mitigates cardiac pathology in a mouse model of left ventricular pressure overload. Am J Physiol Heart Circ Physiol 311(3):H807-H814. https://doi.org/10.1152/ajpheart.00056.2016

Yagi N, Shimizu J, Mohri S, Ji A, Nakamura K, Okuyama H, Toyota H, Morimoto T, Morizane Y, Kurusu M, Miura T, Hashimoto K, Tsujioka K, Suga H, Kajiya F (2004) X-ray diffraction from a left ventricular wall of rat heart. Biophys J 86(4):2286-2294

Open Access This chapter is licensed under the terms of the Creative Commons Attribution 4.0 International License (http://creativecommons.org/licenses/by/4.0/), which permits use, sharing, adaptation, distribution and reproduction in any medium or format, as long as you give appropriate credit to the original author(s) and the source, provide a link to the Creative Commons licence and indicate if changes were made.

The images or other third party material in this chapter are included in the chapter's Creative Commons licence, unless indicated otherwise in a credit line to the material. If material is not included in the chapter's Creative Commons licence and your intended use is not permitted by statutory regulation or exceeds the permitted use, you will need to obtain permission directly from the copyright holder. 